Arq. Bras. Med. Vet. Zootec., v.68, n.3, p.776-784, 2016

\title{
Momento de aplicação do nitrogênio e algumas variáveis estruturais e bromatológicas do capim-massai
}

[Time of nitrogen application and some structural and bromatologic variables of massaigrass]

\author{
M.F. Marques ${ }^{1}$, L.M. Romualdo ${ }^{3}$, J.F. Martinez ${ }^{1}$, C.G. Lima ${ }^{2}$, L.J. Lunardi ${ }^{4}$, \\ P.H.C. Luz ${ }^{2}$, V.R. Herling ${ }^{2}$ \\ ${ }^{1}$ Aluno de pós-graduação - FZEA-USP - Pirassununga, SP \\ ${ }^{2}$ FZEA-USP - Pirassununga, SP \\ ${ }^{3}$ Pós-doutoranda - FZEA-USP - Pirassununga, SP \\ ${ }^{4}$ Aluno de graduação - Unicastelo - Descalvado, SP
}

\begin{abstract}
RESUMO
As plantas forrageiras tropicais apresentam alto potencial de produção de massa de forragem, condicionada às condições edafoclimáticas, principalmente à adubação nitrogenada. A magnitude da resposta depende do sincronismo entre a disponibilidade de nutrientes e as necessidades da planta forrageira na rebrotação, e os resultados encontrados na literatura são contrastantes. Assim, este trabalho foi realizado com o objetivo de avaliar características estruturais e bromatológicas de Panicum maximum Jacq cv. Massai submetido a quatro doses de nitrogênio $\left(0,40,80\right.$ e $\left.120 \mathrm{mg} / \mathrm{dm}^{3}\right)$ e três momentos de aplicação após o corte (um, três e sete dias), divididos em três cortes, em um esquema fatorial $4 \times 3$ e delineado inteiramente ao acaso, com quatro repetições. $\mathrm{O}$ experimento foi conduzido em casa de vegetação. $\mathrm{O}$ incremento na taxa de aparecimento de perfilhos, na densidade populacional de perfilhos, na produção de massa seca de folha total e nos teores de proteína bruta foi de $42 \%, 65 \%, 770 \%$ e $35 \%$, respectivamente, para a dose de $120 \mathrm{mg} / \mathrm{dm}^{3}$ em relação à ausência de adubação nitrogenada. As fibras em detergente neutro e em detergente ácido decresceram cerca de $6 \%$ e $9 \%$, respectivamente, com a adição de nitrogênio. Apenas a massa seca de folha total respondeu às épocas de aplicação de nitrogênio após o corte, com valores pouco expressivos. A adubação nitrogenada exerce efeito positivo sobre as variáveis estudadas, porém novos estudos devem ser conduzidos para a definição da época de adubação de nitrogênio após o corte, para a melhor utilização do nutriente pelas plantas.
\end{abstract}

Palavras-chave: adubação nitrogenada, forragem, perfilhos, Panicum maximum

\begin{abstract}
Tropical forage plants have a high potential for mass production of fodder, subject to soil and climatic conditions, especially with nitrogen fertilization. The magnitude of the response depends on the timing of availability of nutrients and forage plant needs in the regrowth. Thus, this work was carried out to evaluate structural and bromatologic characteristics of the Panicum maximum Jacq Cv. Massai in response to four nitrogen doses $\left(0,40,80\right.$ and $\left.120 \mathrm{mg} / \mathrm{dm}^{3}\right)$ and with three application times after cutting (one, three and seven days) in a $4 \times 3$ factorial treatment combination, in a completely randomized design, with four replicates. The experiment was conducted in a greenhouse. The increase in the rate of tillering, tiller population density, dry mass total leaf production and crude protein levels was $42 \%, 65 \%$, $770 \%$ and $35 \%$, respectively for the dose of $120 \mathrm{mg} / \mathrm{dm}^{3}$ regarding the absence of fertilization. The neutral detergent and acid detergent fibers showed a decrease of 6\% and 9\% with nitrogen addition. Dry mass total leaf production responded to times of nitrogen application after cutting, with little significant values. Nitrogen fertilization has a positive effect on the variables studied, but new studies should be conducted to define the timing of nitrogen fertilization after cutting, for better utilization of this nutrient by plants.
\end{abstract}

Keywords: nitrogen fertilization, forage, tillers, Panicum maximum

Recebido em 8 de junho de 2015

Aceito em 5 de janeiro de 2016

E-mail: mari.marques@usp.br 


\section{INTRODUÇÃO}

As pastagens constituem a fonte de alimento mais importante para a produção de ruminantes no país, o que leva a uma necessidade por plantas mais competitivas, menos exigentes em fertilidade do solo, com menor sazonalidade de produção e mais resistentes a pragas e doenças, entre outros fatores. O lançamento de novos cultivares de gramíneas forrageiras resulta de uma demanda por plantas mais competitivas, menos exigentes em fertilidade do solo, com menor sazonalidade de produção e mais resistentes a pragas e doenças, entre outros fatores. Em 2001, o Centro Nacional de Pesquisa em Gado de Corte (Embrapa) lançou o cultivar massai (Panicum maximum x Panicum infestum). Estudos básicos de ecofisiologia com o cultivar certamente contribuirão para a predição de melhor estratégia de manejo para que a produção e a utilização dessa planta forrageira sejam otimizadas.

A produtividade e a qualidade de uma planta forrageira são influenciadas por inúmeros fatores, como sua escolha, disponibilidade de nutrientes no solo, compreensão dos mecanismos morfofisiológicos e sua interação com o ambiente, entre outros, tornando-se sempre necessária a busca pelas informações na pesquisa para que se possam tomar decisões objetivas de manejo e maximizar a produção animal.

Assim, as variáveis fisiológicas e bromatológicas, como expressão dos processos de crescimento e desenvolvimento do vegetal, podem ter suas eficiências substancialmente melhoradas com o uso de fertilizantes, sobretudo o nitrogênio, por seu efeito positivo na renovação dos tecidos (Duru; Ducrocq, 2000), sempre observando o melhor momento de sua aplicação e da colheita da forragem.

A avaliação da estrutura da pastagem tem despertado muito interesse em experimentos de pastejo. A alta correlação dessa variável com aquelas relacionadas ao consumo torna-a relevante na avaliação do valor nutritivo da pastagem (Heringer, 1997).

A fertilização nitrogenada tem por objetivo melhorar a produção da planta forrageira, bem como a recuperação do nitrogênio aplicado no sistema solo-planta, minimizando suas perdas, sem ocasionar efeitos danosos ao meio ambiente. O nitrogênio possui grande destaque na produção de massa seca, sendo um dos principais nutrientes a proporcionar maior perfilhamento $\mathrm{e}$ produção, bem como melhorias no valor nutritivo da forragem produzida.

Além de sua importância biológica, o nitrogênio é o nutriente mais difícil de ser manejado nos solos de regiões tropicais e subtropicais em virtude do grande número de reações a que está sujeito e a sua alta instabilidade no solo (Ernani, 2003). Devido a isso, a época correta de aplicação do nitrogênio é fundamental para garantir a produtividade; aplicações muito precoces ou muito tardias podem ser pouco aproveitadas pelas plantas (Silva et al., 2005). Para Ramos (1973), a melhor época de aplicação do nitrogênio é durante o perfilhamento.

Estudos de dinâmica de produção das gramíneas forrageiras por meio de avaliações de características bromatológicas e estruturais são essenciais para definição de estratégias de manejo, principalmente para plantas de clima tropical, em que essas características ainda são pouco conhecidas para novos cultivares (Carvalho et al., 2000).

Assim, o presente trabalho foi realizado para avaliar características estruturais e bromatológicas de capim-massai submetido a doses crescentes de nitrogênio, na forma de ureia, aplicadas um, três ou sete dias após o corte.

\section{MATERIAL E MÉTODOS}

O experimento foi conduzido em casa de vegetação no setor de Ciências Agrárias da Faculdade de Zootecnia e Engenharia de Alimentos da Universidade de São Paulo, em Pirassununga-SP. O município de Pirassununga está localizado a $635 \mathrm{~m}$ de altitude (21 ${ }^{\circ} 59^{\prime}$ de latitude sul e $47^{\circ} 26^{\prime}$ de longitude oeste), sendo o clima da região subtropical do tipo Cwa de Köppen, com inverno seco e verão quente e chuvoso (Köppen, Geiger, 1928). O período experimental foi de fevereiro a agosto de 2011.

Quarenta e oito vasos, com capacidade de $6,0 \mathrm{dm}^{3}$, receberam amostras de solo fertilizadas com $375 \mathrm{mg} / \mathrm{dm}^{3}$ de calcário com PRNT de $61 \%$, $250 \mathrm{mg} / \mathrm{dm}^{3}$ de $\mathrm{P}_{2} \mathrm{O}_{5}$ (superfosfato simples) e 
$83,4 \mathrm{mg} / \mathrm{dm}^{3}$ de $\mathrm{K}_{2} \mathrm{O}$ (cloreto de potássio), de acordo com análise de fertilidade $\left(\mathrm{pH}\right.$ em $\mathrm{CaCl}_{2}$ $=5,4 ; \mathrm{P}=6,0 \mathrm{mg} / \mathrm{dm}^{3} ; \mathrm{K}=0,2 \mathrm{mmol}_{\mathrm{c}} / \mathrm{dm}^{3} ; \mathrm{Ca}^{2+}=$ $19 \mathrm{mmol}_{\mathrm{c}} / \mathrm{dm}^{3} ; \mathrm{Mg}^{2}=8 \mathrm{mmol}_{\mathrm{c}} / \mathrm{dm}^{3} ; \mathrm{CTC}=$ $48 \mathrm{mmol}_{\mathrm{c}} / \mathrm{dm}^{3} ; \mathrm{H}+\mathrm{Al}=21 \mathrm{mmol}_{\mathrm{c}} / \mathrm{dm}^{3} ; \mathrm{V}=$ $56 \%)$.

As sementes do capim, com valor cultural de $28 \%$, foram semeadas diretamente nos vasos. Após 21 dias, realizou-se o desbaste das plantas, quando apresentavam aproximadamente $5 \mathrm{~cm}$ de altura, deixando-se quatro plantas por vaso; decorridos mais 21 dias, o corte de uniformização foi feito a uma altura de $10 \mathrm{~cm}$ da superfície do solo.

Os tratamentos avaliados consistiram da combinação de quatro doses de nitrogênio $(0,40$, 80 e $\left.120 \mathrm{mg} / \mathrm{dm}^{3}\right)$ e três momentos de aplicação após o corte (um, três e sete dias), divididos em três cortes, segundo um fatorial 4 x 3 , em um delineamento inteiramente ao acaso, com quatro repetições, totalizando 48 unidades experimentais.

O solo foi mantido a $85 \%$ de sua capacidade de campo com irrigações diárias. Os vasos eram pesados três vezes por semana, para adequação da quantidade de água necessária.

O capim-massai foi cultivado em três períodos de crescimento, tendo 28 dias cada período. As temperaturas médias, mínimas e máximas, na casa de vegetação, foram de $9,3^{\circ} \mathrm{C}$ e $29,8^{\circ} \mathrm{C}$; $10,9^{\circ} \mathrm{C}$ e $31,1^{\circ} \mathrm{C} ; 13,7^{\circ} \mathrm{C}$ e $34,2{ }^{\circ} \mathrm{C}$, para o primeiro, segundo e terceiro períodos, respectivamente. $\mathrm{O}$ primeiro período compreendeu o intervalo entre o corte de uniformização e o primeiro corte de fato $(5 \mathrm{de}$ julho de 2011); o segundo período foi do primeiro ao segundo corte ( 2 de agosto de 2011) e o terceiro período foi do segundo ao terceiro corte (30 de agosto de 2011). As doses de nitrogênio (ureia) foram parceladas e aplicadas em solução no início de cada período, considerando o momento de aplicação de um, três e sete dias. No início de cada período e no final do experimento, todos os perfilhos do vaso eram contados para determinação da taxa de aparecimento de perfilhos (TApP) e da densidade populacional de perfilhos (DPP).
No último dia de cada período de avaliação, a parte aérea da planta foi cortada a $10 \mathrm{~cm}$ da superfície do solo, o material foi levado ao laboratório para pesagem e secagem em estufa de circulação forçada de ar a $65^{\circ} \mathrm{C}$ até atingir massa constante, determinada pelo peso, que foi quantificado em balança analítica. Com esse material, foram realizadas determinações de massa seca (MS), conforme os métodos descritos por Silva e Queiroz (2002); fibra em detergente neutro (FDN) e fibra em detergente ácido (FDA), segundo o método de Van Soest (1963); e nitrogênio total (NT), de acordo com o método descrito por Malavolta et al. (1997). Posteriormente, com base nessa informação, foi calculada a porcentagem de proteína bruta (PB), utilizando-se a seguinte equação: $\mathrm{PB}=\mathrm{NT} \mathrm{x}$ 6,25 .

Os resultados foram submetidos à análise da variância, considerando-se como fontes de variação a dose de N, a época de aplicação e a interação dose e época, testados a $5 \%$ de probabilidade. Considerou-se também como fonte de variação cada período de crescimento, denominado como medida repetida no tempo. A interação foi desdobrada, ou não, de acordo com a significância considerada de 5\%, e, dependendo da importância, os graus de liberdade foram desdobrados no estudo de regressão. Para as variáveis corte e época de aplicação, quando seus efeitos foram significativos sem a interação com doses de nitrogênio, as médias dos tratamentos foram estimadas utilizando-se "LSMEANS", e, para a comparação entre elas, foi realizado o teste de Tukey a 5\% de probabilidade (SAS, 1989).

\section{RESULTADOS E DISCUSSÃO}

Foi observada uma interação significativa $(\mathrm{P}<0,05)$ entre o nível de adubação nitrogenada e o número do corte sobre a taxa de aparecimento de perfilho (TApP) (Fig. 1). Foi observado um aumento linear na TApP com o nível de $\mathrm{N}$ para os cortes 2 e $3(\mathrm{P}<0,05)$, e uma associação quadrática para o primeiro corte $(\mathrm{P}<0,05)$.

A TApP com ausência de aplicação de nitrogênio foi de $30,94 \%$, e com $120 \mathrm{mg} / \mathrm{dm}^{3}$ de $\mathrm{N}$ de $53,2 \%$, aumento de $42 \%$, percentuais próximos aos encontrados por Pereira et al. (2011), que, quando trabalharam com capim-mombaça em três densidades de cultivo e adubado com 
nitrogênio, obtiveram 34,9 e 46,0\% de TApP na ausência e na presença de N (320kg/ha), respectivamente. É fácil observar que o capimmassai tem como característica marcante o perfilhamento intenso. Com dose de $\mathrm{N}$ de aproximadamente três vezes menos, a TApP foi praticamente a mesma do capim-mombaça pertencente ao mesmo gênero Panicum. O nitrogênio influencia a densidade de perfilhos e, consequentemente, a produção de massa seca. $\mathrm{O}$ primeiro efeito do nitrogênio é promover o aparecimento de perfilhos e, em seguida, fortalecer os já existentes, ou seja, torná-los mais vigorosos (Carámbula, 1981).

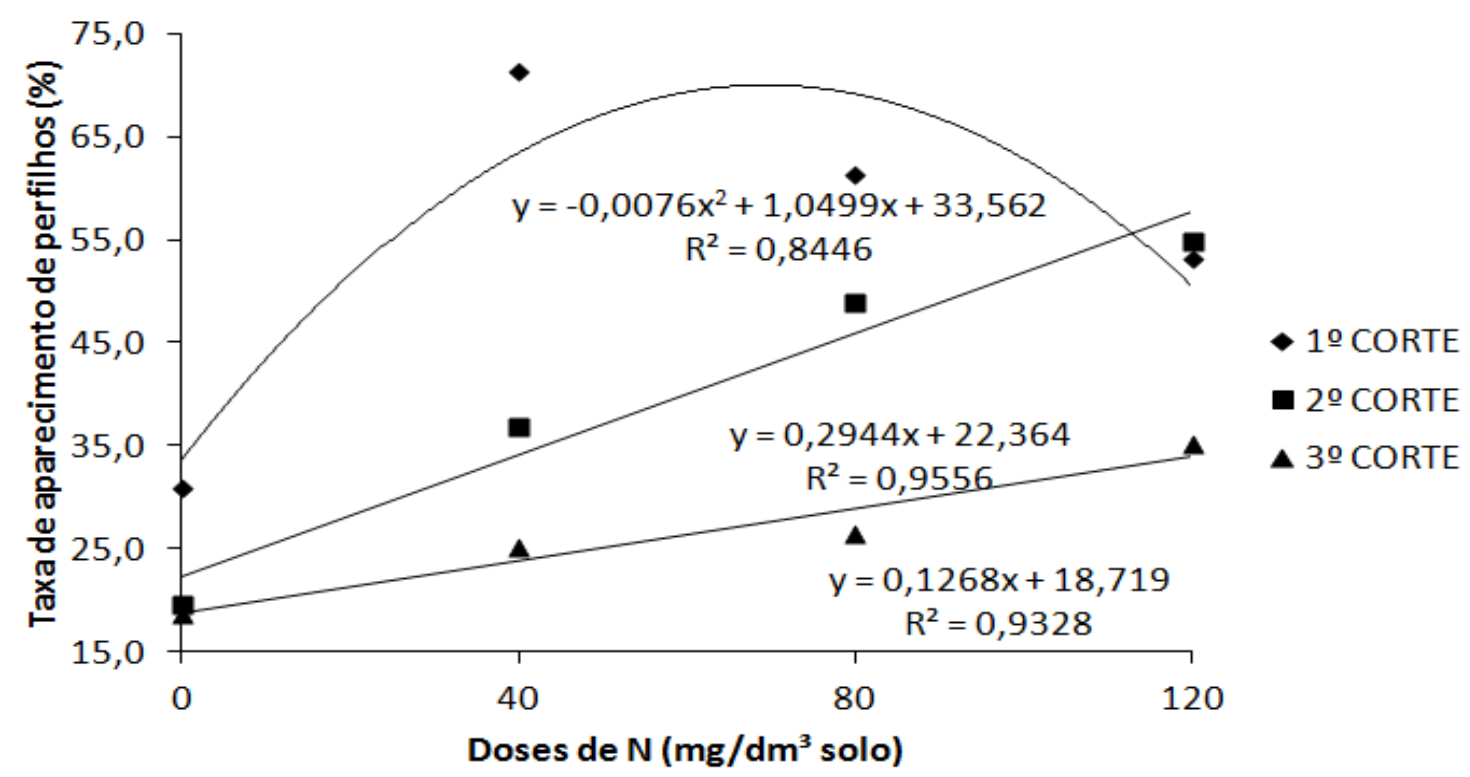

Figura 1. Efeito de dose de nitrogênio $(\mathrm{N})$ e de corte na taxa de aparecimento de perfilhos (TApP) de plantas de capim-massai, cultivadas em vasos em casa de vegetação.

De acordo com Lemaire (1985), deficiências de nitrogênio determinam baixos valores de ocupação de sítios e mantêm a TApP abaixo dos seus valores potenciais, mesmo em dosséis com baixo índice de área foliar.

A taxa de aparecimento de perfilhos na ausência de competição é decorrente do sincronismo entre o desenvolvimento das folhas e o perfilhamento, gerando-se o conceito de "ocupação de sítios" (Davies, 1974).

No primeiro crescimento, o comportamento da taxa de aparecimento de perfilhos foi quadrático, com ponto de máxima na dose de $69 \mathrm{mg} \cdot \mathrm{dm}^{-3}$, com alta ocupação de sítios, o que diminui no decorrer dos outros dois crescimentos com taxa de aparecimento de 0,29 e 0,13 perfilhos para cada $1 \mathrm{mg} . \mathrm{dm}^{-3}$ de nitrogênio aplicado, respectivamente para o segundo e terceiro crescimentos.
A densidade populacional de perfilho (DPP) teve efeito da interação $(\mathrm{P}<0,05)$ entre doses de nitrogênio $(\mathrm{N})$ e cortes e entre doses de nitrogênio (N) e momento de aplicação de nitrogênio após o corte.

Houve comportamento quadrático da DPP, nos três crescimentos, com aumentos de 38, 51 e $65 \%$ no número de perfilhos para as doses de 40 , 80 e $120 \mathrm{mg} / \mathrm{dm}^{3}$ de $\mathrm{N}$, respectivamente, em relação às plantas que não receberam adubação nitrogenada (Fig. 2). Martuscello et al. (2006) observaram aumentos da ordem de 26,30 e $61 \%$, que apresentaram diferença significativa apenas nas doses de 80 e $120 \mathrm{mg} / \mathrm{dm}^{3}$ de nitrogênio, aplicados ao capim-massai. Apesar de não seguir um padrão, a aplicação de $80 \mathrm{mg} / \mathrm{dm}^{3}$ aos três ou sete dias após o corte seria a mais indicada $(71,6$ e 66,7 perfilhos por vaso, respectivamente), enquanto para a dose de $120 \mathrm{mg} / \mathrm{dm}^{3}$ seria aos sete dias (74,3 perfilhos por vaso) de rebrotação. 
Apesar de o capim-massai ter apresentado taxa de aparecimento de perfilhos decrescente do primeiro ao terceiro crescimentos, a densidade populacional de perfilhos foi crescente do primeiro ao terceiro crescimentos.

A resposta positiva do perfilhamento à adubação nitrogenada pode estar associada ao estímulo do nitrogênio no crescimento e na multiplicação de células vegetais, uma vez que esse nutriente é constituinte de proteínas e ácidos nucleicos celulares. Nabinger (1996) afirmou que a deficiência de nitrogênio aumenta o número de gemas dormentes, enquanto o suprimento permite o máximo perfilhamento.

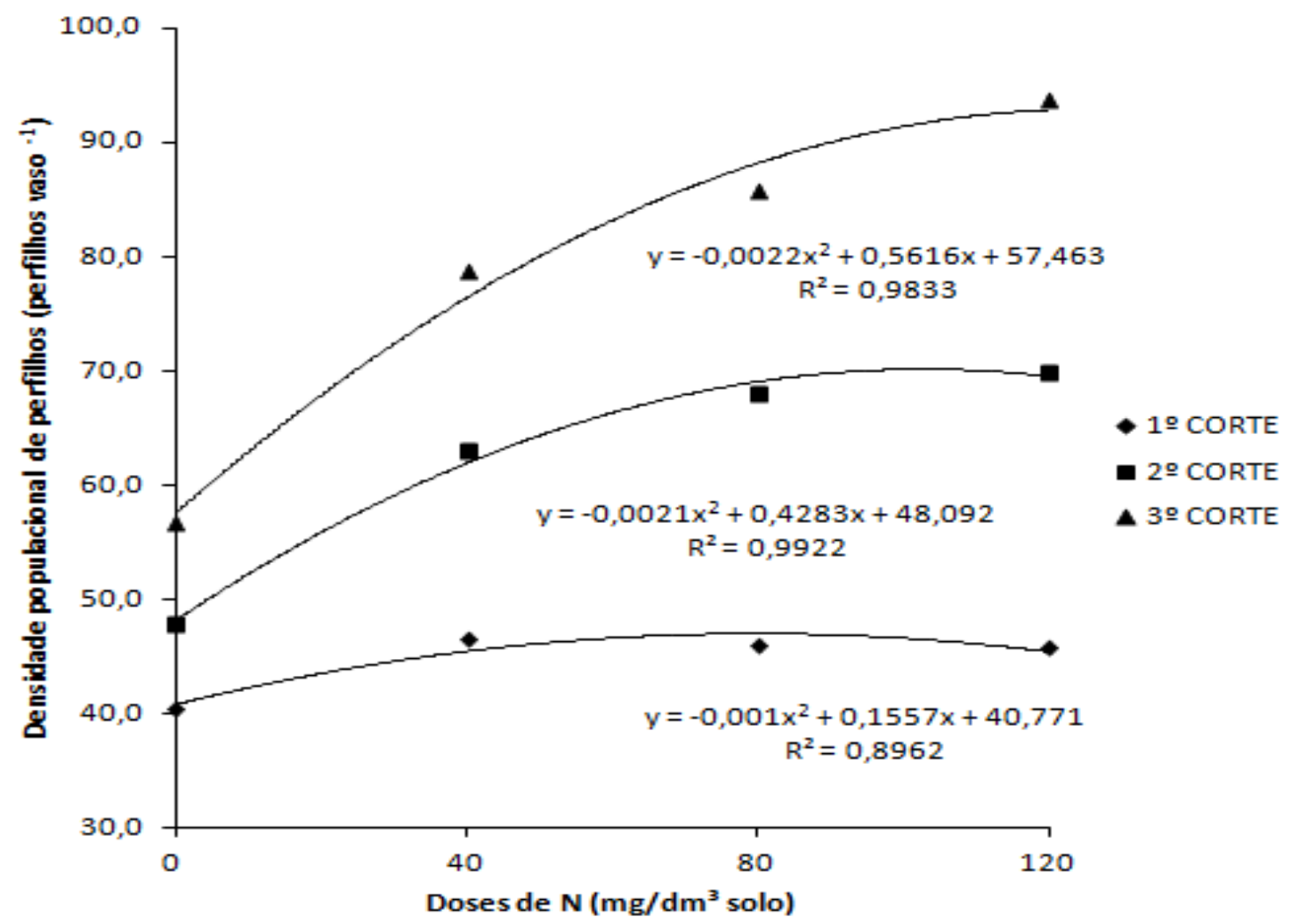

Figura 2. Efeito de dose de nitrogênio $(\mathrm{N})$ e de corte na densidade populacional de perfilhos (DPP) de plantas de capim-massai, cultivadas em vasos em casa de vegetação.

Garcez Neto et al. (2002) verificaram efeito expressivo do suprimento de $\mathrm{N}$ no número total de perfilhos (21\% na densidade populacional de perfilhos). Segundo esses autores, o perfilhamento em gramíneas é uma característica estrutural determinante da plasticidade morfogênica das plantas forrageiras, influenciada por combinações de fatores nutricionais, ambientais e de manejo nas características morfogênicas.

Houve interação $(\mathrm{P}<0,05)$ entre doses de nitrogênio e cortes, bem como interação entre momentos de aplicação de nitrogênio após o corte e cortes na massa seca de folha total (MSFT).
No decorrer dos cortes, observou-se que a aplicação crescente de nitrogênio favoreceu $o$ aumento linear da MSFT no primeiro e terceiro cortes, da ordem de 0,0047 e 0,0363 g MS.mg ${ }^{-1}$ de $\mathrm{N}$ aplicado, respectivamente. No segundo corte, houve maior variação na resposta, com efeito cúbico (Fig. 3). O aumento na produção de MSFT apresentou incremento de até $770 \%$ na maior dose de nitrogênio $\left(120 \mathrm{mg} / \mathrm{dm}^{3}\right)$ no terceiro corte, sendo bem maior que a observada por Garcez Neto et al. (2002), que registraram variação de $456 \%$ na maior dose de nitrogênio $\left(200 \mathrm{mg} / \mathrm{dm}^{3}\right)$ em capim-mombaça.

Para todos os momentos de aplicação de $\mathrm{N}$ após o corte, no terceiro corte observaram-se as 
maiores MSFT, da ordem de 3,16; 2,40 e $2,91 \mathrm{~g} /$ vaso, para um, três e sete dias após o corte, respectivamente. Ao se analisarem os momentos de aplicação de $\mathrm{N}$ em cada corte, observa-se que apenas no segundo (sete dias após o corte $2,09 \mathrm{~g} / \mathrm{vaso}$ ) e no terceiro corte (um dia após o corte - 3,16g/vaso) ocorreram diferenças entre as médias.

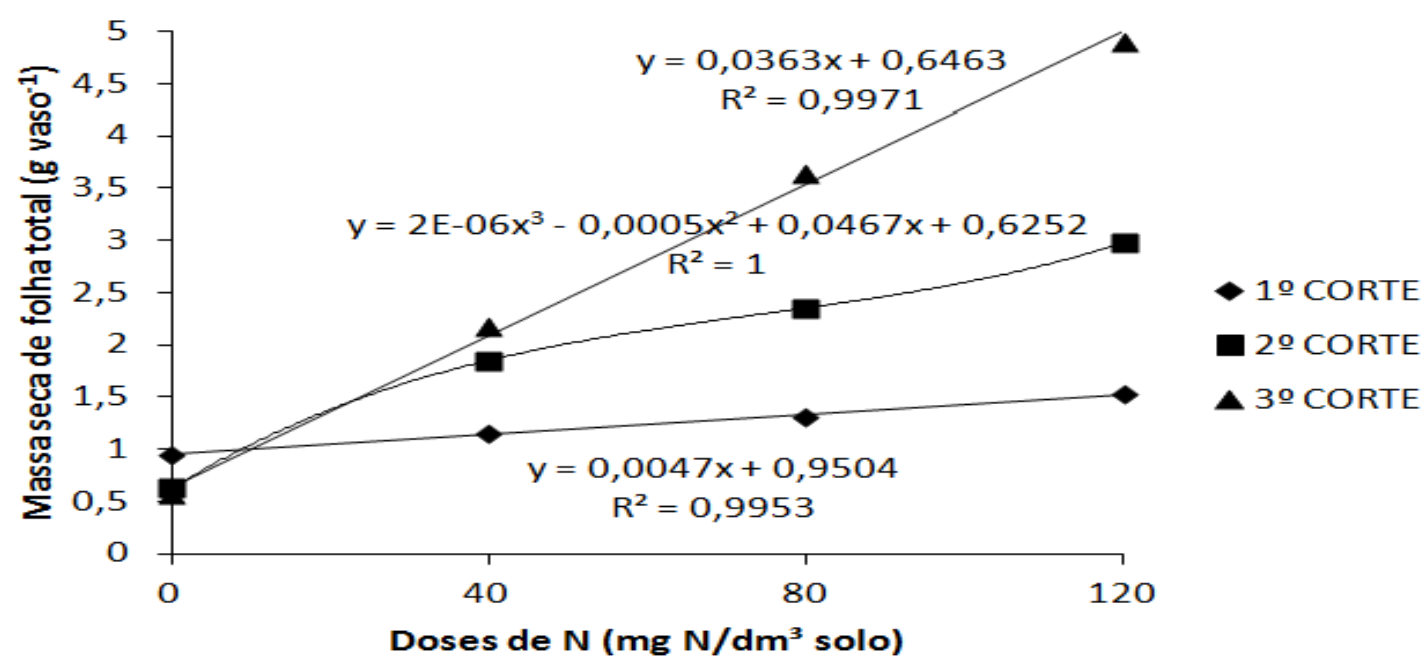

Figura 3. Efeito das doses de nitrogênio (N) e dos cortes na massa seca de folha total (MSFT) de plantas de capim-massai, cultivadas em vasos em casa de vegetação.

A adubação nitrogenada tem efeito direto marcante na área foliar fotossintetizante, como consequência do aumento na taxa de alongamento foliar, que revela a importância do nitrogênio para o acréscimo na produção de forragem. Esses resultados corroboram os descritos por Martuscello et al. (2006) e Garcez Neto et al. (2002) sobre o efeito do nitrogênio na produção de MS.

Com relação à proteína bruta, houve interação $(\mathrm{P}<0,05)$ entre doses de nitrogênio e cortes, com efeito linear para o primeiro e terceiro cortes e quadrático para o segundo. À medida que se aumentaram as doses de nitrogênio, ocorreu aumento linear no teor médio de proteína bruta, para o primeiro e terceiro cortes, enquanto que para o segundo corte o comportamento foi quadrático, com ponto de máximo teor de $\mathrm{PB}$ na dose de $100 \mathrm{~kg}$ de N/ha As médias dos teores de proteína bruta variaram de $10,23 \%$, para o tratamento sem nitrogênio, a $15,80 \%$, na maior dose de nitrogênio aplicada, para o primeiro corte (aumento de 35\%) (Fig. 4). Teores próximos foram encontrados por Benett et al. (2008), quando trabalharam com fontes e doses de nitrogênio para capim-marandu e verificaram variações nos teores de $\mathrm{PB}$ de $10,65 \%$ para
$17,67 \%$, para o tratamento testemunha, na maior dose de nitrogênio aplicada $(200 \mathrm{~kg} / \mathrm{ha})$.

Segundo Van Soest (1994), quando plantas forrageiras apresentam teores de proteína bruta inferiores a 7\%, ocorre redução na digestão dela devido a inadequados níveis de nitrogênio para os microrganismos do rúmen, diminuindo sua população e, consequentemente, reduzindo a digestibilidade e a ingestão da massa seca. Assim, um teor mais alto de PB é necessário para o atendimento das exigências proteicas do organismo animal.

$\mathrm{O}$ teor de fibra em detergente neutro (FDN) revelou efeito significativo $(\mathrm{P}<0,05)$ para cortes e para doses de nitrogênio. Quando se analisou o efeito da época de corte para os teores de FDN, observou-se que, no segundo corte, os teores foram superiores aos demais $(73,04 \%)$.

Esse resultado difere do encontrado por Dias et al. (2000), que, ao realizarem adubação nitrogenada em forrageiras tropicais, observaram maior teor de FDN no terceiro corte, e não era esperado, uma vez que maiores teores de FDN se associam à maior produção de matéria seca. 


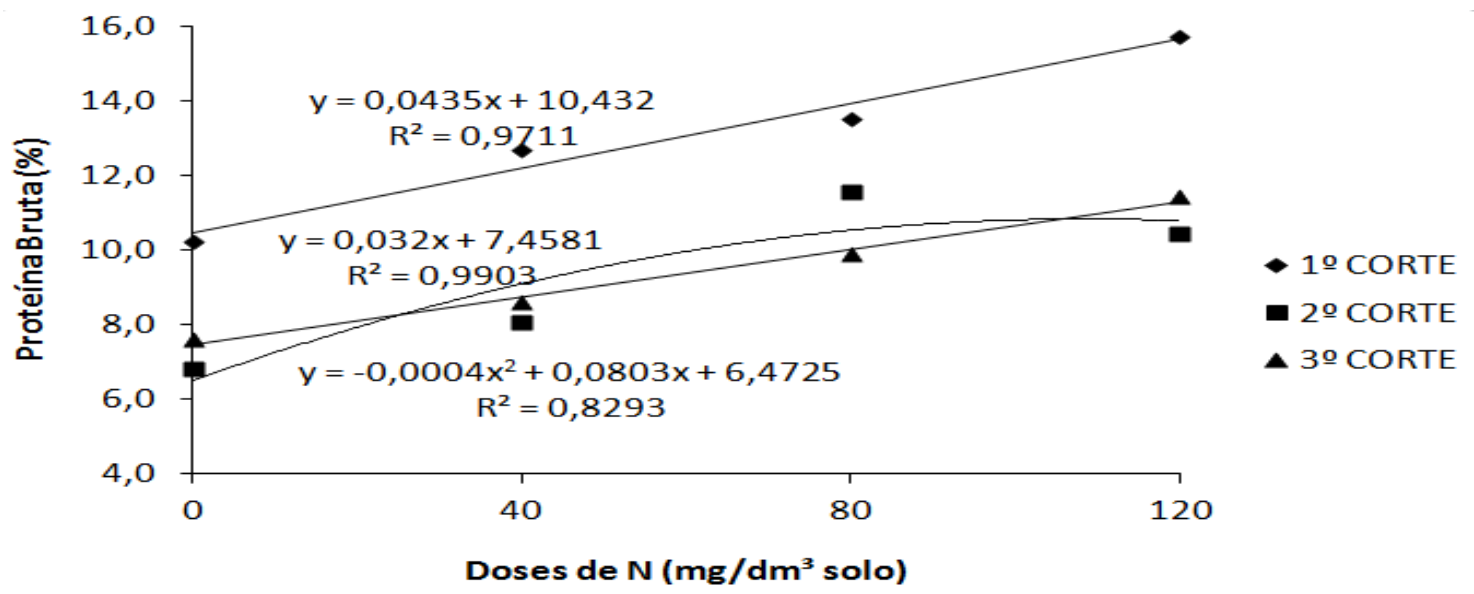

Figura 4. Efeito de dose de nitrogênio $(\mathrm{N})$ e de corte nos teores de proteína bruta $(\mathrm{PB})$ de plantas de capim-massai, cultivadas em vasos em casa de vegetação

Com relação à adubação nitrogenada, constatouse comportamento linear negativo de acordo com as doses crescentes de nitrogênio aplicadas ao solo (redução de 6\%) (Fig.5). Esses resultados são semelhantes aos obtidos por Cecato et al. (2004), que utilizaram diferentes doses de nitrogênio $(0,200,400$ e $600 \mathrm{~kg} / \mathrm{ha})$ na Brachiaria brizantha.
Os teores de fibra em detergente ácido (FDA) apresentaram interação significativa $(\mathrm{P}<0.05)$ para doses de nitrogênio e cortes. As plantas foram influenciadas pelas doses crescentes de nitrogênio aplicadas ao solo, o que demonstra comportamento quadrático, para o segundo e terceiro cortes. Já para o primeiro corte, não houve efeito significativo.

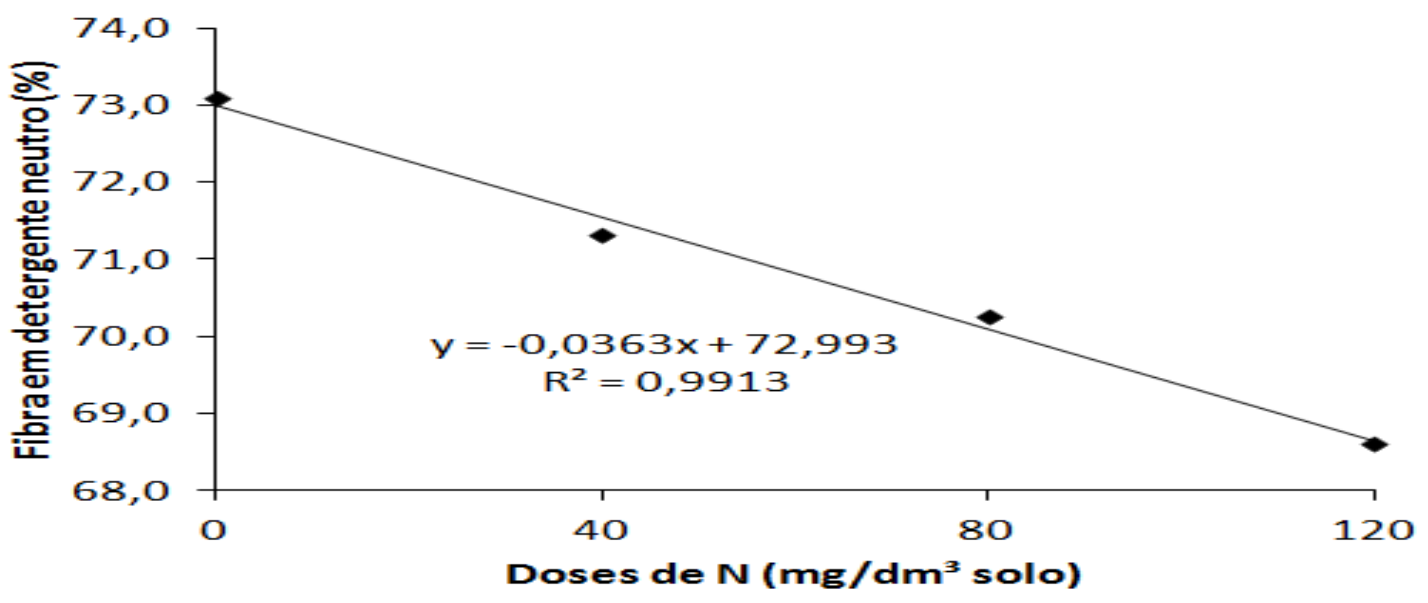

Figura 5. Teores de fibra em detergente neutro (FDN) em função das doses de N aplicadas em plantas de capim-massai, cultivadas em vasos em casa de vegetação.

Os teores de FDA diminuíram com o incremento nas doses de nitrogênio ( $9 \%$ em média), apresentando valores médios de 36,5\% (Fig. 6). Esses resultados foram semelhantes aos encontrados por Magalhães et al. (2005), quando trabalharam com doses crescentes de nitrogênio $(0,100,200$ e $300 \mathrm{~kg} / \mathrm{ha} / \mathrm{ano})$ e fósforo $(0,50$ e $100 \mathrm{~kg} / \mathrm{ha} / \mathrm{ano}$ ) para o capim Brachiaria decumbens. Também, Gargantini (2005), ao trabalhar com doses de nitrogênio $(0,25,50$ e $100 \mathrm{~kg} / \mathrm{ha} /$ corte) para o capim-mombaça, verificou decréscimos nos teores de FDA com aumento nas doses de nitrogênio. Segundo Nussio et al. (1998), forragens com valores de FDA em torno de $40 \%$ ou mais apresentam baixo consumo e menor digestibilidade. 


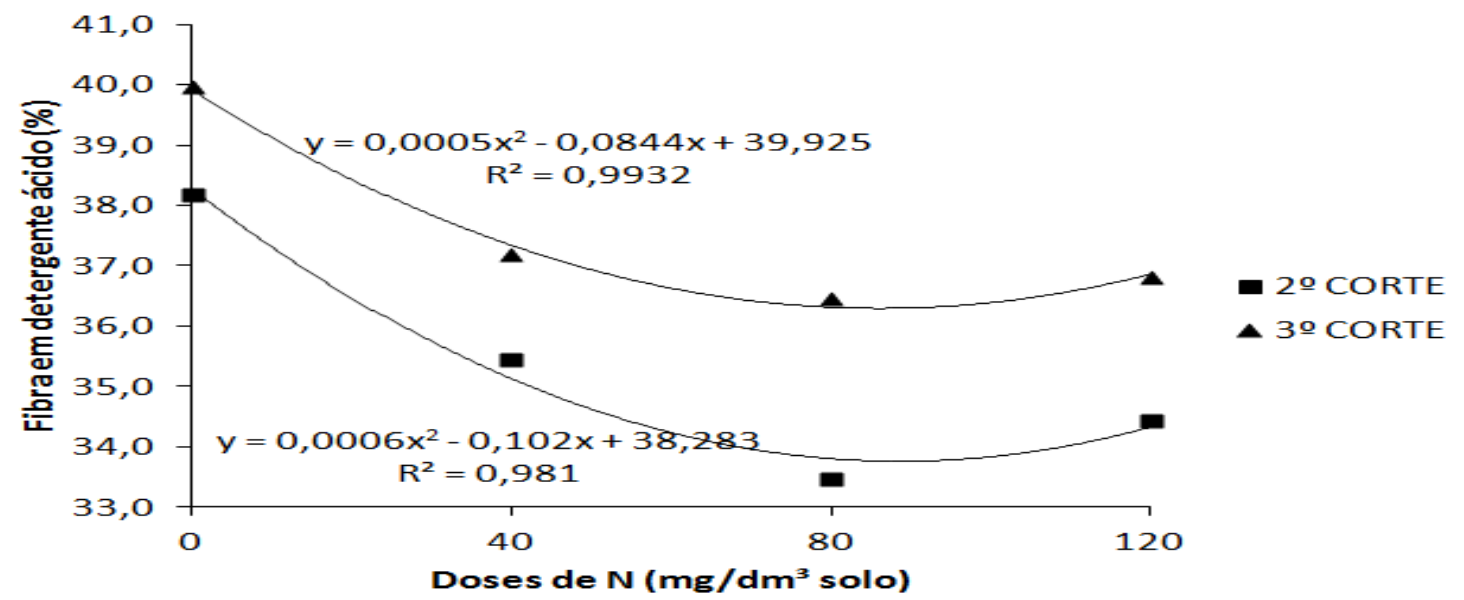

Figura 6. Efeito de dose de nitrogênio $(\mathrm{N})$ e de corte nos teores de fibra em detergente ácido (FDA) de plantas de capim-massai, cultivadas em vasos em casa de vegetação.

Redução nos teores de FDA implicaria possível melhoria da digestibilidade da forragem. A esse respeito, Van Soest (1994) menciona que o nitrogênio provoca aumento na concentração de aminoácidos e proteínas que se acumulam principalmente no conteúdo celular, acarretando diluição da parede celular e aumento de digestibilidade. Por sua vez, isso pode ser contrabalançado pelo aumento da lignificação dessa parede, na presença de uma adubação nitrogenada adequada para o bom crescimento da planta. Pelo balanço desses fatores, segundo esse autor, alterações na digestibilidade de toda ordem, atribuídas à fertilização nitrogenada, têm sido relatadas.

\section{CONCLUSÃO}

O nitrogênio é benéfico à estrutura das plantas, revelado pela renovação de tecidos em decorrência de seus efeitos positivos na taxa de aparecimento de perfilhos e na densidade populacional de perfilhos. $\mathrm{O}$ nitrogênio possibilitou melhoria da produção e da composição químico-bromatológica do capim, pelo melhor equilíbrio entre o conteúdo celular e os componentes da parede celular, representados pela proteína bruta e pelas fibras em detergente neutro e em detergente ácido. $\mathrm{O}$ momento de aplicação do nitrogênio após o corte teve efeito pouco expressivo e apenas para a massa seca de folha total. A adubação nitrogenada exerce efeito positivo nas características estudadas, porém novos estudos devem ser conduzidos para a definição do melhor momento para a adubação de $\mathrm{N}$ após o corte, para seu melhor aproveitamento pelas plantas.

\section{REFERÊNCIAS}

BENETT, C.G.S.; BUZETTI, S.; SILVA, K.S. et al. Produtividade e composição bromatológica do capim-marandu a fontes e doses de nitrogênio. Ciênc. Agrotecnol.. v.32, p.16291636, 2008.

CARÁMBULA, M. Producción de semillas de plantas forrageiras. Montevideo: Editorial Agropecuária, 1981. 518f.

CARVALHO, C.A.B.; SILVA, S.C.; SBRISSIA, A.F. et al. Demografia de perfilhamento e taxas de acúmulo de matéria seca em capim "tifton 85 " sob pastejo. Sci. Agríc., v.57, p.591-600, 2000.

CECATO, U.; PEREIRA, L.A.F.; JOBIM, C.C. Influência das adubações nitrogenadas e fosfatadas sobre a composição químicobromatológica do capim-Marandu (Brachiaria brizantha) (Hochst) Stapf cv Marandu). Acta Sci., v.26, p.409-416, 2004.

DAVIES, A. Leaf tissue remaining after cutting and regrowth in perennial ryegrass. J. Agricult. Sci., v.82, p.165-172, 1974.

DIAS, P.F.; ROCHA, G.P.; ROCHA FILHO, R.R. Produção e valor nutritivo de gramíneas forrageiras tropicais, avaliadas no período das águas, sob diferentes doses de nitrogênio. Ciênc. Agrotecnol., v.24, p. 260-271, 2000. 
DURU, M.; DUCROCQ, H. Growth and senescence of the successive leaves of a tiller ontogenic development and effect of temperature. Ann. Bot., v.85, p.635-643, 2000.

ERNANI, P. R. Disponibilidade de nitrogênio e adubação nitrogenada para macieira. Lages: Graphel, 2003. 76p.

GARCEZ NETO, A.F.; NASCIMENTO JUNIOR, D.; REGAZZI, A.J. et al. Respostas morfogênicas e estruturais de Panicum maximum cv. Mombaça sob diferentes níveis de adubação nitrogenada e alturas de corte. Rev. Bras. Zootec., v.31, p.1890-1900, 2002.

GARGANTINI, P.E. Irrigação e adubação nitrogenada em capim-Mombaça (Panicum maximum Jacq.) na região oeste do Estado de São Paulo. 2005. 95f. Dissertação (Mestrado) Universidade Estadual Paulista "Julio de Mesquita Filho", Ilha Solteira, SP.

HERINGER, I.; MOOJEN, E.L.; LUPATI NI, G.C.; SOARES, A.B. Estrutura de uma pastagem de milheto (Pennisetum americanum (L.) Leeke) sob dois níveis de nitrogênio em pastejo contínuo. In: REUNIÃO DA SOCIEDADE BRASILEIRA DE ZOOTECNIA, 34., 1997, Juiz de Fora. Anais... Juiz de Fora: SBZ, 1997, p.1315.

KÖPPEN, W.; GEIGER, R. Klimate der Erde. Gotha: Verlag Justus Perthes, 1928. (Wall-map $150 \mathrm{~cm} \times 200 \mathrm{~cm})$.

LEMAIRE, G. Cinétique de la croissance d'um peuplement de fétuque élevée (Festuca arundinacea Schreb.) pendant l'hiver et lê printemps. 1985. 96f. Thèse (Doctorat) Université de Caen, France. 1985.

MAGALHÃES, A.F.; PIRES, A.J.V.; CARVALHO, G.G.P. Composição bromatológica do capim Brachiaria decumbens Stapf adubado com doses crescentes de nitrogênio e de fósforo. In: REUNIÃO ANUAL DA SOCIEDADE BRASILEIRA DE ZOOTECNIA, 42., 2005, Goiânia. Anais... Goiânia: SBZ, 2005. CD-ROM.

MALAVOLTA, E.; VITTI, G.C.; OLIVEIRA, S.A. Avaliação do estado nutricional das plantas: princípios e aplicações. 2.ed. Piracicaba: POTAFOS, 319 p. 1997.
MARTUSCELLO, J.A.; FONSECA, D.M.; NASCIMENTO JÚNIOR, D. et al. Características morfogênicas e estruturais de capim-massai submetido a adubação nitrogenada e desfolhação. Rev. Bras. Zootec., v.35, p.665$671,2006$.

NABINGER, C. Princípios da exploração intensiva de pastagens. In: SIMPÓSIO SOBRE MANEJO DA PASTAGEM, 13., 1996. Piracicaba. Anais... Piracicaba: FEALQ, 1996. p.15-95.

NUSSIO, L.G.; MANZANO, R.P.; PEDREIRA, C.G.S. Valor alimentício em plantas do gênero Cynodon. In: SIMPÓSIO SOBRE MANEJO DA PASTAGEM, 15., 1998, Piracicaba. Anais... Piracicaba: FEALQ/ESALQ, 1998. p.203-242.

PEREIRA, V.V.; FONSECA, D.M.; MARTUSCELLO, J.A.; BRAZ, T.G.S. et al. Características morfogênicas e estruturais de capim-mombaça em três densidades de cultivo adubado com nitrogênio. Rev. Bras. Zootec., v.40, p.2681-2689, 2011.

RAMOS, M. Efeitos do nitrogênio e fósforo sobre características agronômicas da variedade de trigo IAS 54 e suas relações com a produção. Pesqu. Agropecu. Bras., v.8, p.213-216, 1973.

SAS/STAT User's Guide. Version 6. 4.ed. Cary, NC: SAS Institute Inc., 1989. Vol.2, 846p.

SILVA, D.J.; QUEIROZ, A.C. Análise de alimentos: métodos químicos e biológicos. 3.ed. Viçosa: UFV, 2002. 235p.

SILVA， P.R.F.; STRIEDER， M.L.; COSER, R.P.S.; RAMBO, L. et al. Grain yield and kernel protein content increases of maize hybrids with late nitrogen side-dresses. Sci. Agríc., v.62, p.487-492, 2005.

VAN SOEST, P.J. Nutritional ecology of the ruminant. 2.ed. New York: Cornell University, 1994.

VAN SOEST, P.J. Use of detergents in the analysis of fibrous feeds. II. A rapid method for the determination of fiber and lignin. J. Assoc. Offic. Anal. Chem., v.46, p.829, 1963. 